\title{
Truncated Cables1 causes agenesis of the corpus callosum in mice
}

\author{
Seiya Mizuno ${ }^{1,6}$, Dinh TH Tra ${ }^{1,6}$, Atsushi Mizobuchi ${ }^{1}$, Hiroyoshi Iseki ${ }^{1,2}$, Saori Mizuno-lijima ${ }^{1}$, Jun-Dal Kim ${ }^{3}$, \\ Junji Ishida ${ }^{3}$, Yoichi Matsuda ${ }^{4}$, Satoshi Kunita ${ }^{5}$, Akiyoshi Fukamizu ${ }^{3}$, Fumihiro Sugiyama ${ }^{1}$ and Ken-ichi Yagami ${ }^{1}$
}

Agenesis of the corpus callosum (ACC) is a congenital abnormality of the brain structure. More than 60 genes are known to be involved in corpus callosum development. However, the molecular mechanisms underlying ACC are not fully understood. Previously, we produced a novel transgenic mouse strain, TAS, carrying genes of the tetracycline-inducible expression system that are not involved in brain development, and inherited ACC was observed in the brains of all homozygous TAS mice. Although ACC was probably induced by transgene insertion mutation, the causative gene and the molecular mechanism of its pathogenesis remain unclear. Here, we first performed interphase three-color fluorescence in situ hybridization (FISH) analysis to determine the genomic insertion site. Transgenes were inserted into chromosome $18 \sim 12.0 \mathrm{Mb}$ from the centromere. Gene expression analysis and genomic PCR walking showed that the genomic region containing exon 4 of Cables 1 was deleted by transgene insertion and the other exons of Cables 1 were intact. The mutant allele was designated as Cables $1^{\text {TAS }}$. Interestingly, Cables $1^{\text {TAS }}$ mRNA consisted of exons 1-3 of Cables 1 and part of the transgene that encoded a novel truncated Cables1 protein. Homozygous TAS mice exhibited mRNA expression of Cables $1^{\text {TAS }}$ in the fetal cerebrum, but not that of wild-type Cables 1. To investigate whether a dominant negative effect of Cables $1^{\text {TAS }}$ or complete loss of function of Cables1 gives rise to ACC, we produced Cables1-null mutant mice. ACC was not observed in Cables 1-null mutant mice, suggesting that a dominant negative effect of Cables $1^{\text {TAS }}$ impairs callosal formation. Moreover, ACC frequency in Cables $1^{+ \text {TAS }}$ mice was significantly lower than that in Cables $1^{- \text {TAS }}$ mice, indicating that wild-type Cables 1 interfered with the dominant negative effect of Cables $1^{\text {TAS }}$. This study indicated that truncated Cables 1 causes ACC and wild-type Cables1 contributes to callosal formation.

Laboratory Investigation (2014) 94, 321-330; doi:10.1038/labinvest.2013.146; published online 16 December 2013

KEYWORDS: ACC; Cables1-null mutant mice; TAS mouse; transgene insertion mutation; truncated Cables1

The corpus callosum is the largest fiber tract in the brain, consisting of 200-350 million and 7 million fibers in humans and mice, respectively, ${ }^{1,2}$ and serves as a bridge to transfer information between the right and left cerebral hemispheres. Agenesis of the corpus callosum (ACC), which is characterized by absence of the corpus callosum, ${ }^{3}$ is a congenital brain abnormality that may occur in isolation or in association with other central nervous system or systemic malformations in humans. Neonatal and prenatal imaging studies have suggested that ACC occurs in at least 1:4000 live births in the human population., ${ }^{4,5}$ In other studies, the estimated incidence rates of ACC were reported as $3-5 \%$ of patients with neurodevelopmental disorders and $2-3 \%$ of the population with mental impairment. ${ }^{6-8}$

Reverse genetic analyses of mice identified more than 60 causative genes of ACC, and these genes are involved in several processes in the formation of corpus callous. ${ }^{9}$ The Sp8, Pax6, and Otx2 genes are essential for patterning of the developing forebrain. Analyses of mouse strains with mutations in these genes indicated their involvement in ACC with multiple brain malformations and strong craniofacial abnormalities. ${ }^{10-12}$ As both brain midline fusion defects and ACC were observed in several inbred mouse strains (eg, BALBc/Wah1 and 129/J), ${ }^{13}$ telencephalic

\footnotetext{
'Laboratory Animal Resource Center, University of Tsukuba, Tsukuba, Japan; ${ }^{2}$ Project Research Division, Research Center for Genomic Medicine, Saitama Medical University, Saitama, Japan; ${ }^{3}$ Life Science Center, Tsukuba Advanced Research Alliance, Graduate School of Life and Environmental Sciences, University of Tsukuba, Tsukuba, Japan; ${ }^{4}$ Laboratory of Animal Genetics, Graduate School of Bioagricultural Sciences, Nagoya University, Nagoya, Japan and ${ }^{5}$ Center for Experimental Medicine, Jichi Medical University, Shimotsuke, Japan

Correspondence: Dr F Sugiyama, PhD, Laboratory Animal Resource Center, University of Tsukuba, 1-1-1 Tennodai, Tsukuba 305-8575, Japan.

E-mail: bunbun@md.tsukuba.ac.jp

${ }^{6}$ These authors contributed equally to this work.

Received 27 August 2013; revised 7 November 2013; accepted 8 November 2013
} 
midline fusion appears to be necessary for corpus callosum development. Correct development of the cerebral cortex is also important for formation of the corpus callosum because callosal neurons, which extend axons across the corpus callosum, are located in the cerebral cortex. Indeed, $\mathrm{N}$ cadherin gene-mutant mice showed ACC because of abnormal development of the cerebral cortex. ${ }^{14}$ Furthermore, the projection of callosal axons from the cortex is regulated by various axon guidance molecules, including Slit/Robo, Netrin/ DCC, Ephs/Ephrins, and Semaphorins/Neuropilins. Indeed, abnormal corpus callosum development has been reported in mice with deficiencies in these genes. ${ }^{15-22}$

Occasionally, random integration of transgene DNA into the host genome disrupts an endogenous gene and causes a class of mutations called transgene insertion mutations. ${ }^{23}$ Approximately $5-15 \%$ of random DNA insertion events in transgenic mice are associated with an abnormal phenotype by transgene insertion mutation. ${ }^{24}$ The integrated transgene may affect endogenous loci close to the transgene and result in inactivation of the endogenous gene or creation of a fusion with an endogenous gene. When transgene insertion mutation results in unexpected phenotypic alterations in mice, knowledge regarding the precise location of transgene insertion within the genome could be useful to discover genes responsible for defects.

Previously, we developed a transgenic mouse strain, TAS (reverse tetracycline-controlled transactivator and tetracycline-controlled transcriptional silencer), that showed ACC accompanied with formation of Probst bundles, as seen in human patients. ${ }^{25}$ The complete penetrance of ACC was observed in homozygous TAS mice. Furthermore, axons of the corpus callosum were not repelled by the midline structures. TAS mice carry both the reverse tetracyclinecontrolled transactivator (rtTA) gene and the tetracyclinecontrolled transcriptional silencer gene (tTS) in the BALB/c genetic background. As these transgene products do not affect brain development and another founder line carrying both rtTA and tTS did not exhibit ACC, we hypothesized that ACC in TAS was caused by transgene insertion mutation. In addition, we reported previously that rtTA and tTS were located in the region between 9.3 and $16.9 \mathrm{Mb}$ from the centromere on chromosome 18 in TAS, and there is no critical gene known to be involved in ACC in the candidate genomic region.

Although ACC in TAS mice is probably induced by transgene insertion mutation, the causative gene and its pathological mechanism have not yet been clarified. Here, we identified the genomic insertion site of the transgene on chromosome 18 at $\sim 12 \mathrm{Mb}$ from the centromere by multicolor fluorescence in situ hybridization (FISH) analysis. Furthermore, the insertional mutation was shown to generate a novel mutant Cables1 allele. Analysis of Cables1-null mutant mice indicated that complete loss of function of Cables1 did not contribute to callosal malformation. Finally, we demonstrated that the frequency of ACC in Cables $1^{+/ T A S}$ mice was significantly lower than that in Cables $1^{-/ T A S}$ mice. These data suggest that ACC in TAS mice is caused by the $\mathrm{N}$-terminal half of Cables1, a molecule responsible for the complex organization of the corpus callosum.

\section{MATERIALS AND METHODS Animals}

The TAS mice used in this study have been described previously. ${ }^{25} \mathrm{BALB} / \mathrm{cAJ}, \mathrm{C} 57 \mathrm{BL} / 6 \mathrm{~J}$, and ICR mice were purchased from CLEA Japan. Animals were kept as described previously. ${ }^{25}$ Animal experiments were carried out humanely in accordance with the Regulations for Animal Experiments of the University of Tsukuba and Fundamental Guidelines for Proper Conduct of Animal Experiment and Related Activities in Academic Research Institutions under the jurisdiction of the Ministry of Education, Culture, Sports, Science, and Technology of Japan and with approval from the Institutional Animal Experiment Committee of our university.

\section{KB Staining}

The brains of adult mice were rapidly immersed in $10 \%$ neutral buffered formalin for at least 1 week before embedding. Subsequently, brains were dehydrated by passage through an ascending series of alcohol concentrations, cleared in xylene, and embedded in paraffin. Paraffin blocks were cut into serial sections $6 \mu \mathrm{m}$ thick on a microtome and mounted on glass slides. Sections were stained with Klüver-Barrera (KB) stain according to standard protocols.

\section{Immunofluorescence}

The neonatal brains were fixed in $4 \%$ paraformaldehyde in PBS. After overnight fixation at $4{ }^{\circ} \mathrm{C}$, the brains were cryoprotected in 30\% sucrose and frozen in OCT compound (Sakura Finetek). Cryostat sections $30 \mu \mathrm{m}$ thick were blocked with $0.2 \%$ Triton X-100 in SuperBlock ${ }^{\circledR}$ Blocking Buffer in TBS (Pierce). The sections were incubated with rat anti-L1CAM antibody (1:100; Millipore). Subsequently, the sections were washed in PBS and incubated with mouse Cy3-GFAP antibody (1:200; Sigma) and Alexa Fluor 350 goat anti-rat IgG (1:200; Life Technologies).

\section{FISH}

R-banded chromosome preparations were made from the spleen lymphocytes of heterozygous TAS mice as previously described. ${ }^{25}$ After hardening at $65^{\circ} \mathrm{C}$, the chromosome spreads were denatured in $70 \%$ formamide $/ 2 \times$ SSC for $2 \mathrm{~min}$, then dehydrated in ethanol (70 and $100 \%)$ at $4{ }^{\circ} \mathrm{C}$ for 15 min. RP23-232N9 and RP23-101N14 bacterial artificial chromosome (BAC) DNAs were purified by NucleoBond BAC 100 (Macherey-Nagel). These BAC and tTS DNA probes were labeled by nick translation (Roche) with biotin-dUTP (Roche), Cy3-dUTP (GE Healthcare), and Cy-5-dUTP (GE Healthcare), respectively. Repeat sequences in BAC DNA probes were blocked with $10 \mu \mathrm{g}$ Cot1 DNA (Life Technologies). Aliquots of $1 \mu \mathrm{g}$ of each $\mathrm{BAC}$ probe and 
$500 \mathrm{ng}$ of tTS DNA probe in formamide were denatured at $75^{\circ} \mathrm{C}$ for $10 \mathrm{~min}$ and applied to slides with hybridization buffer containing $200 \mu \mathrm{g} / \mu \mathrm{l}$ dextran sulfate sodium salt (Sigma), $200 \mu \mathrm{g} / \mu \mathrm{l}$ bovine serum albumin (Roche), and $2 \times$ SSC. After overnight hybridization at $37^{\circ} \mathrm{C}$, the slides were washed in $1 \times, 2 \times$, and $4 \times$ SSC and incubated with avidin-FITC (Roche) at $37^{\circ} \mathrm{C}$ for $1 \mathrm{~h}$.

\section{RT-PCR}

Total RNA was prepared from the brains of embryos using ISOGEN (Nippon Gene). cDNA was synthesized as described previously. ${ }^{25}$ PCR was performed with AmpliTaq Gold ${ }^{\circledR}$ PCR Master Mix (Life Technologies) and various primers (Supplementary Table 1).

\section{Sequencing}

Genomic and cDNA sequencing analyses were performed with a BigDye ${ }^{\circledR}$ Terminator v3.1 Cycle Sequencing Kit and Applied Biosystems 3130 Genetic Analyzer (Life Technologies).

\section{Northern Blotting}

Aliquots of $10 \mu \mathrm{g}$ of total mouse embryonic cerebral RNA (E17.5 and E19.5) were denatured, fractionated, and transferred onto Hybond $\mathrm{N}^{+}$(GE Healthcare) according to standard protocols. The $5^{\prime}$ - and $3^{\prime}$-cDNA probes were derived from mouse brain cDNA with specific primers (Supplementary Table 2). Hybridization and detection were performed using a DIG Northern Starter Kit (Roche).

\section{Transfection and Western Blotting}

cDNA fragments of Cables1 and Cables $1{ }^{\text {TAS }}$ CDS, which were derived from wild-type and TAS mice, were introduced into the pc3 mammalian expression vector. These constructs were transfected into HEK293T cells by LipofectAMINE LTX (Life Technologies). Cables1 and Cables ${ }^{\text {TAS }}$ proteins from transfected cells were detected with rabbit anti-N-terminal Cables 1 antibody (M280; 1:100; Santa Cruz) and HRP-conjugated donkey anti-rabbit IgG secondary antibody (1:4000; GE Healthcare).

\section{Gene Targeting}

The Cables $1^{\text {null }}$ targeting vector contained the Neo ${ }^{r}$ cassette (Figure 5a). The 3.8-kb 5'-homology arm and 4.6-kb $3^{\prime}$-homology arm were amplified from BALB/c mouse genomic DNA with Cables ${ }^{\text {null }}$ specific primers (Supplementary Table 3). The Cables $1^{\text {null }}$ targeting vector was introduced into $\mathrm{BALB} / \mathrm{c}$ embryonic stem cells by electroporation. ${ }^{26}$ Genomic DNA from G418-resistant colonies were screened for homologous recombination by Southern blotting.

\section{RESULTS}

\section{Identification of Transgene Insertion Site in TAS Mice}

We recently developed a novel transgenic mouse strain carrying rtTA and tTS, the components of the Tet-on/off gene expression system. Unexpectedly, only one line of transgenic mice showed ACC (Figure 1b), designated as TAS. ${ }^{25}$ As rtTA and tTS have not been reported to affect cerebral development, we hypothesized that ACC in TAS mice was due to disruption of an endogenous gene by transgene insertion. A recent study showed that both rTA and tTS transgenes are closely linked and inserted into the region between 9.3 and $16.9 \mathrm{Mb}$ from the centromere on chromosome 18 in TAS mice.

To narrow down the insertion site, we performed threecolor FISH analyses. The DNA probes from BAC clones RP23-232N9 (derived from chr.18: 11108363 to 11290545 ) and RP23-101N14 (derived from chr.18: 12743636 to 12933 531) were labeled with $\mathrm{Cy} 3$ and $\mathrm{Cy} 5$, respectively. A transgenic DNA probe was labeled with FITC. Although these three-color signals were detected on chromosome 18, the signals were not separated on metaphase chromosome spreads (Figure 2a). In contrast, the FITC signal was detected between $\mathrm{Cy} 3$ and $\mathrm{Cy} 5$ signals on interphase chromosome spreads (Figure $2 \mathrm{~b}$ ). These observations indicated transgene insertion in the region between 11.3 and $12.7 \mathrm{Mb}$ on chromosome 18 (Figure 2c). We then examined the expression of 14 genes located around the region of transgene insertion (Figure 2c). RT-PCR analyses indicated that only the Cables 1 gene expression pattern was different between TAS and wildtype mice (Figure $2 \mathrm{~d}$ ).

\section{Exon 4 of Cables 1 Is Disrupted by Transgene Insertion}

The Cables 1 gene is located $12 \mathrm{Mb}$ from the centromere on mouse chromosome 18. Cables 1 consists of 10 exons, and alternative splicing results in two transcripts. Exon 4 of Cables1 isoform I is not included in isoform II (Figure 4c). We performed genomic PCR walking in the Cables1 locus to determine the transgene insertion site. Consistent with the results of RT-PCR analyses, long-PCR (data not shown) and sequence analyses (Figure 3a) showed that the genomic region from 12058849 to $12070825 \mathrm{bp}$ on chromosome 18, including exon 4 of Cables1, was deleted by transgenes insertion (Figure 3b). The novel mutant allele of Cables 1 was designated as Cables ${ }^{\text {TAS }}$. As multiple copies of the transgenes (rtTA and tTS) were inserted into the genome, ${ }^{25}$ no amplification product was obtained from Cables ${ }^{\text {TAS }}$ by genomic PCR analysis with a primer set derived from the $5^{\prime}$ and $3^{\prime}$ flanking regions of the deletion (data not shown).

\section{De Novo Truncating Mutation in Cables 1}

No amplification of Cables1 cDNA was observed in TAS homozygous mutant mice by RT-PCR analysis using primers derived from exons 2 and 7 (Figure 2d). In addition, genomic analysis revealed that only exon 4 of Cables1 was deleted (Figure $3 \mathrm{~b}$ ). These results suggested that truncated Cables 1 mRNA, including exons 1-3, may be expressed in TAS mice. Next, we investigated Cables1 expression in the fetal cerebrum at E17.5 and 19.5, because the corpus callosum dramatically develops late in gestation. Northern blotting 


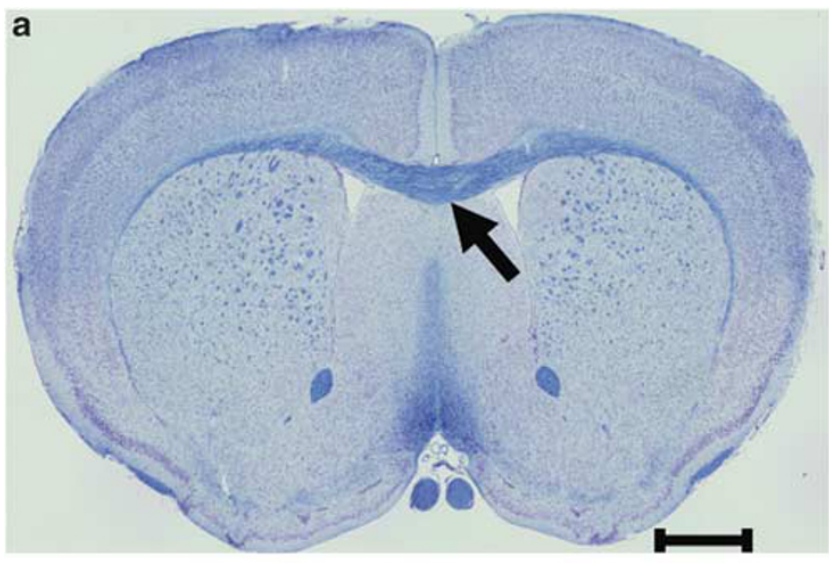

Wild type

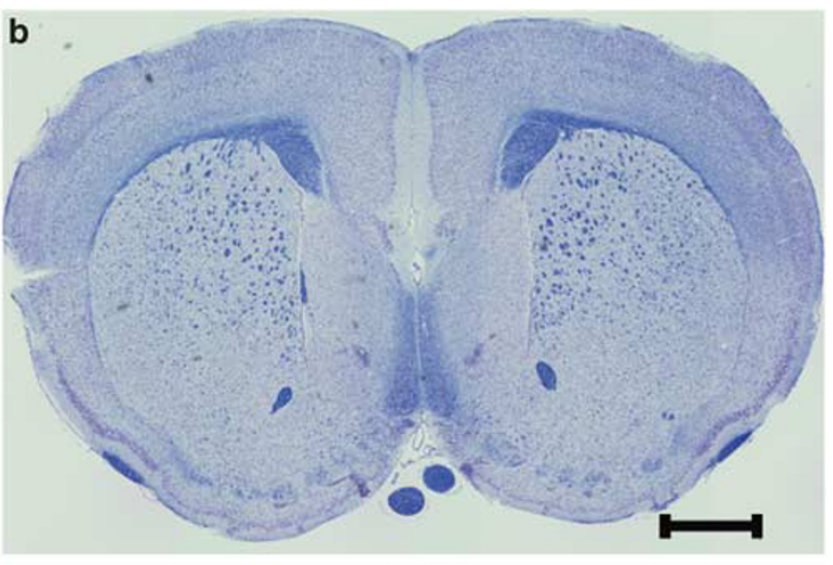

TAS

Figure 1 Agenesis of the corpus callosum in TAS. Coronal sections through the rostral levels of the cerebrum in adult wild-type (a) and adult TAS (b) mice were stained with Klüver-Barrera (KB). Arrow indicates the corpus callosum; scale bar $=1 \mathrm{~mm}(\mathbf{a}, \mathbf{b})$.

analysis with 5'-cDNA probe (derived from part of exons 1-3) revealed that Cables1 mRNA was shorter in TAS fetuses $\left(\right.$ Cables $\left.1^{\text {TAS/TAS }}\right)$ than in wild-type fetuses. In contrast, no band was detected in TAS fetuses $\left(\right.$ Cables $\left.1^{\text {TAS/TAS }}\right)$ with $3^{\prime}$-cDNA probe derived from exons 7-9 (Figure 4a). These results suggested that exons $1-3$ of Cables 1 are included in Cables $1^{\text {TAS }}$ mRNA and the other exons are not transcribed in TAS $\left(\right.$ Cables $\left.1^{\text {TAS/TAS }}\right)$. In addition, Cables $1^{\text {TAS }}$ mRNA more than $2 \mathrm{~kb}$ in length was detected with $5^{\prime}$-cDNA probe, even though a 1425-bp fragment comprising exons 1-3 of Cables1. Sequence analysis was then performed to investigate Cable$s 1^{\text {TAS }}$ mRNA in detail. Interestingly, exons 1-3 of Cables 1 mRNA were linked to the transgene in Cablest ${ }^{T A S}$ (Figure $4 \mathrm{~b}$ ). Furthermore, a frameshift mutation was detected in the transgene following exon 3 of the Cables $1^{T A S}$ transcript, resulting in a stop codon (TAG) $69 \mathrm{bp}$ downstream from the exon 1-3 boundary (Figure 4c).

To confirm whether a mutant small protein is translated from Cables1 ${ }^{T A S}$, HEK293T cells were transfected with Cables $1^{\text {TAS }}$ or wild-type Cables1 expression vector. As expected, western blotting analysis with an antibody to the $\mathrm{N}$-terminus of Cables1 (M-280) indicated that mutant protein derived from Cables $1^{\text {TAS }}$ was smaller than the wildtype protein (Figure 4d). Furthermore, the molecular weight of the mutant protein product from Cables $1^{\text {TAS }}$ was similar to the predicted size $(33.5 \mathrm{kDa})$. These results suggested that the abnormal truncated (N-terminal half) Cables1 protein could be expressed in TAS mice. Western blotting analysis was then performed to detect truncated Cables 1 in the brain of these mice. However, anti-Cables1 antibody (M-280) did not specifically detect wild-type or truncated Cables1 protein in brain lysate (data not shown).

\section{Development of Normal Corpus Callosum in Cables1- Null Mutant Mice}

Although reverse genetics analyses indicated various abnormalities in Cables1-deficient mice (eg, development of endometrial hyperplasia, progression of colon cancer, and poor oocyte quality), ${ }^{27-29}$ the effect of Cables1-null mutation on the corpus callosum has not been reported. To determine whether null or TAS mutation gives rise to ACC, it is necessary to establish Cables1-deficient mice in the BALB/c genetic background, because ACC in TAS was seen with the $\mathrm{BALB} / \mathrm{c}$ (not C57BL/6) genetic background. ${ }^{25}$ We successfully produced Cables1-null mutant mice in the BALB/c genetic background (Figures $5 \mathrm{a}-\mathrm{c}$ ). The targeting vector was introduced into BALB/c embryonic stem cells by electroporation. ${ }^{26}$ Five distinct clones were obtained, one of which (clone 10) was used to generate germline chimeras by aggregation with tetraploid ICR mouse embryos. Cables ${ }^{-/-}$ mice were obtained from intercrosses of Cables $1^{-/+}$mice at Mendelian ratios. These mice were genotyped by genomic Southern blotting (Figure 5b), and RT-PCR analysis with primers derived from exons 2 and 7 revealed that Cables 1 was not expressed in Cables1 ${ }^{-/-}$mice (Figure $5 \mathrm{c}$ ). We then confirmed that a normal corpus callosum was formed in the brains of all Cables $1^{-1-}$ adult mice examined $(n=7$; Figure 5d). These data indicated that lack of Cables 1 function is not responsible for ACC in TAS mice.

\section{Relationship between Cables1 Genotype and ACC}

To understand the relationship between the Cables1 genotype and ACC phenotype in more detail, Cables1 $1^{+/ T A S}$ mice were crossed with Cables1 ${ }^{-1-}$ mice. As a result, we obtained eight Cables $1^{+/ T A S}$ and 6 Cables $1^{-/ \text {TAS }}$ mice and examined gross callosum structures at 0 days of age by immunofluorescence with L1-CAM and GFAP antibodies. Similar to Cables $1^{\text {TAS/TAS }}$, all of the Cables1 $1^{-/ T A S}$ mice showed ACC (Figure 6b). In our previous study, all Cables $1^{\text {TAS/TAS }}$ $(n=12)$ and $62 \%$ of Cables $1^{+/ T A S}(n=37)$ mice developed ACC. ${ }^{25}$ The Cables 1 genotypes and frequency of ACC are summarized in Table 1. Taken together, these results indicated that ACC occurred only in mice bearing the Cables $1^{\text {TAS }}$ allele. These data indicated that ACC is caused not 

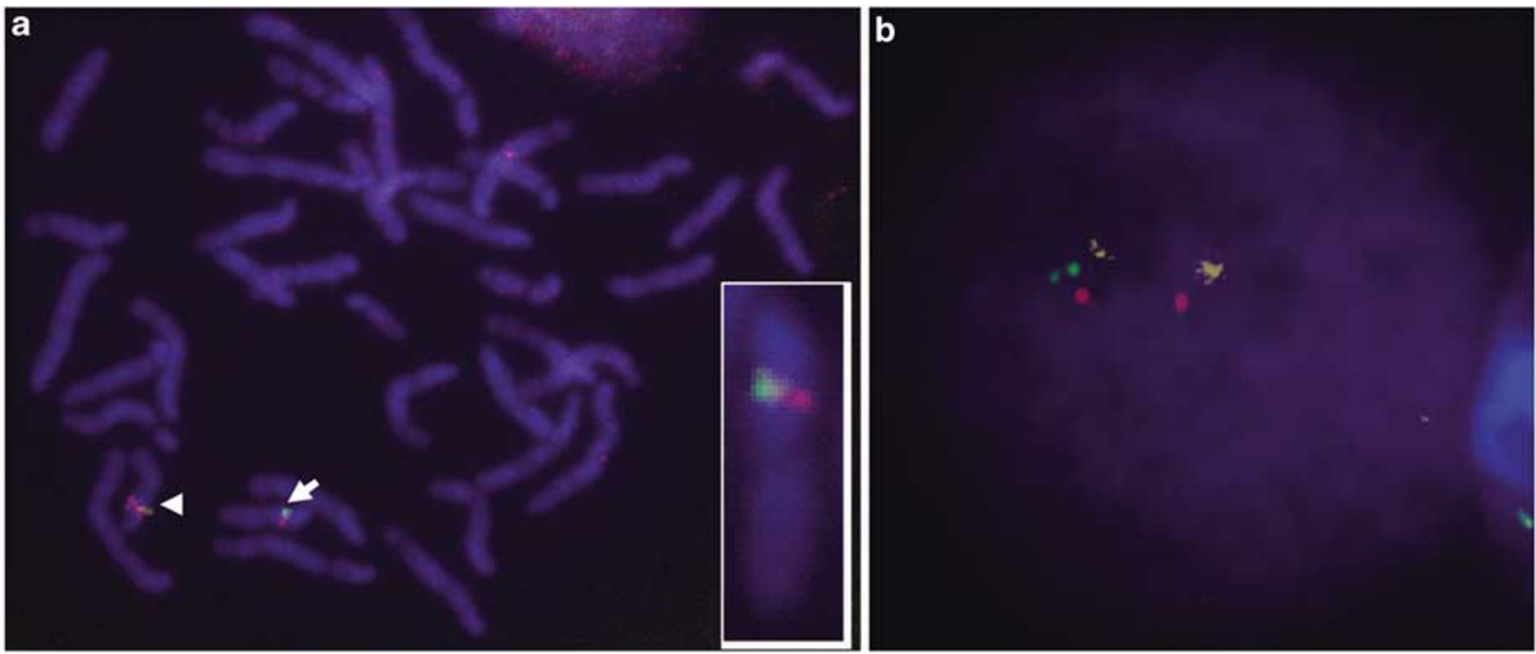

C

Chr. 18
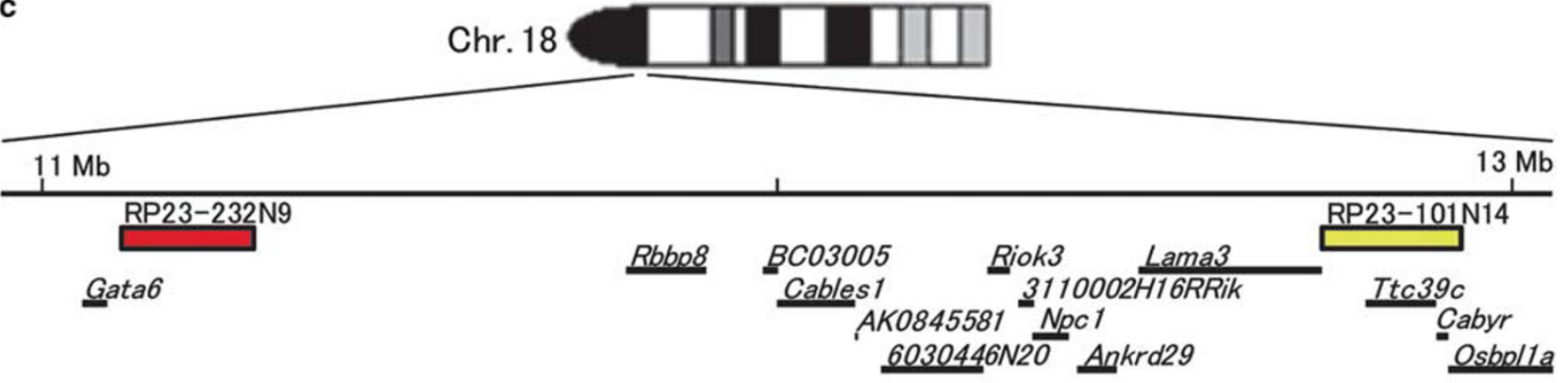

d
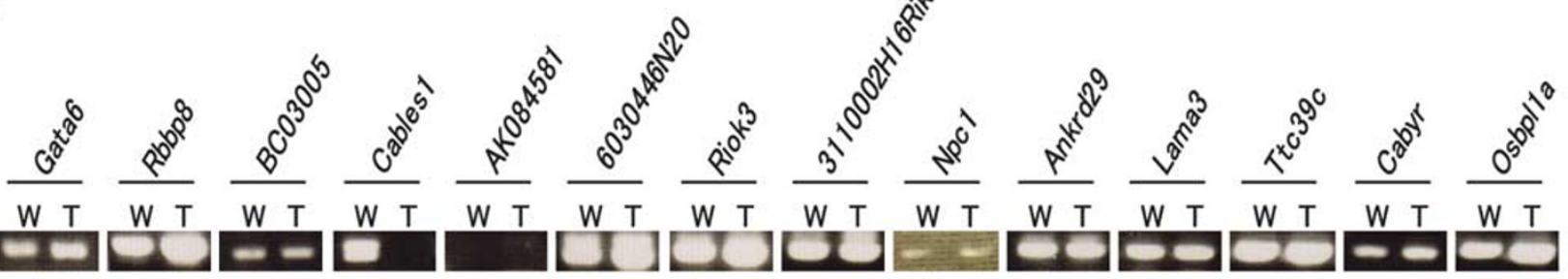

Figure 2 Identification of transgene insertion site. (a) FISH to metaphase heterozygous TAS chromosome spreads. The arrow indicates transgene (green) signals colocalized with RP23-232N9 (red) and RP23-101N14 (yellow). The white box shows an enlarged view of this chromosome and indicates that the three-color signals are not separated. The arrowhead indicates red and yellow signals on the nontransgenic chromosome. (b) FISH to interphase heterozygous TAS chromosome spreads. Transgene (green) signals were observed between RP23-232N9 (red) and RP23-101N14 (yellow) signals. (c) The genomic region between RP23-232N9 (red box) and RP32-101N14 (yellow box) contains 14 known and predicted genes. (d) RT-PCR analysis of the 14 genes showed that only the Cables 1 gene expression pattern was different between TAS and wild-type mice. W, wild-type mouse; T, TAS mouse.

by loss of Cables1 function but by Cables $1^{\text {TAS }}$ mutation. Interestingly, as ACC frequency in Cables $1^{+/ T A S}$ mice was lower than that in Cables $1^{- \text {ITAS }}$ mice, wild-type Cables1 interfered with the dominant negative effect of Cables $1^{\text {TAS }}$, suggesting that wild-type Cables1 may be involved in corpus callosum development.

\section{DISCUSSION}

TAS mice are a useful model in which to investigate genes involved in regulation of corpus callosum development and to gain new insights into the molecular genetics of ACC. ${ }^{25}$ Here we showed that exon 4 of Cables 1 was deleted by transgene insertion mutation in TAS mice. We also showed that the abnormal Cables $1 \mathrm{mRNA}$, which is composed of exons 1-3 of Cables 1 and a short part of the transgene, was expressed in the TAS mouse fetal brain. In addition, truncated Cables1 protein was shown to be generated from Cables ${ }^{T A S}$ transcript. The callosal appearance in Cables1-null mutant mice supported the conclusion that ACC in TAS mice is because of the dominant negative effect of Cables ${ }^{\text {TAS }}$ mutation on callosal organization. Moreover, we showed the relationship between Cables1 genotype and ACC, demonstrating the contribution of wild-type Cables1 to callosal formation.

Three-color interphase FISH analyses revealed transgene insertion in the region between 11.3 and $12.7 \mathrm{Mb}$ from the centromere of chromosome 18 in TAC mice (Figures $2 \mathrm{~b}$ 

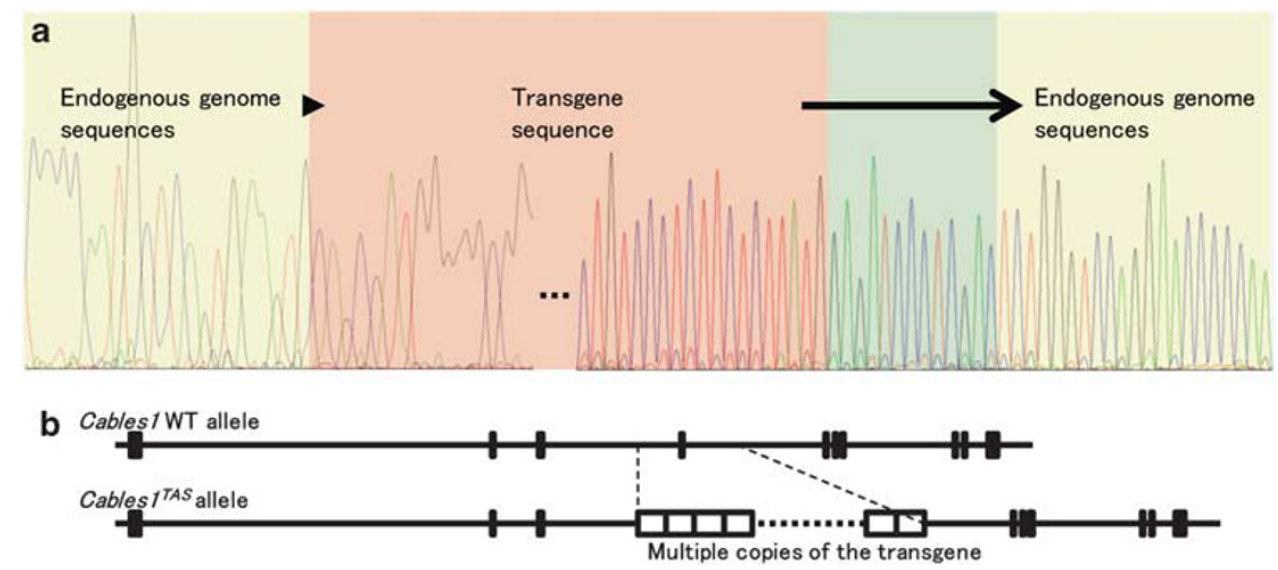

Figure 3 Disruption of Cables1 gene caused by transgene insertion. (a) Results of genomic sequencing analysis. The transgenic sequence (red background) was directly connected (arrowhead) to 5585 bp upstream of exon 4 of Cables 1 (yellow background). The $3^{\prime}$-end of the transgene connected (arrow) to neither the genomic nor transgenic sequence (green background) and subsequently connected to 6314 bp downstream of exon 4 (red background). Dotted line indicates multiple copies of the transgene. (b) The schematic diagram shows a comparison of Cables 1 genomic structure between wild-type and TAS alleles.

a

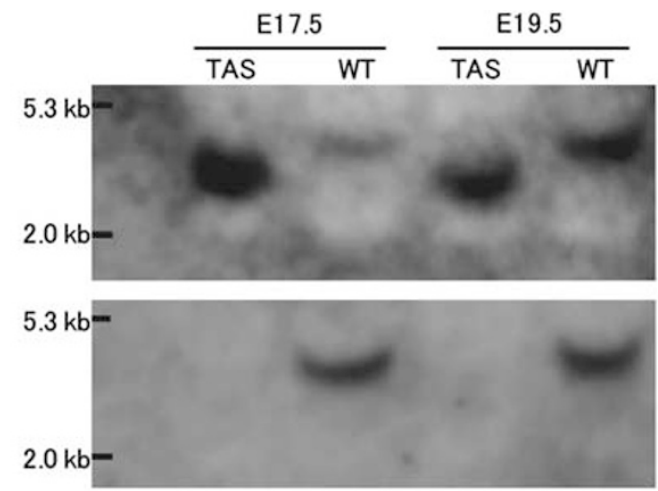

C

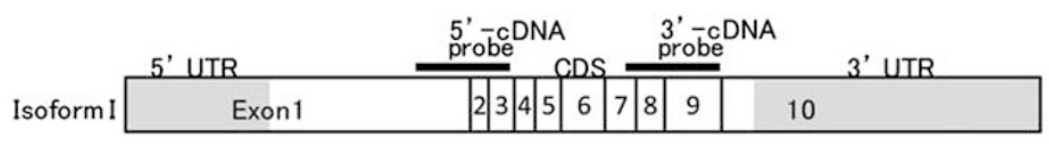

Isoform I

Exon

Cables $1^{\text {TAS }}$

\begin{tabular}{|l|l|l|l|}
\hline Exon 1 & 2 & 3 & Transgene \\
\hline
\end{tabular}

b

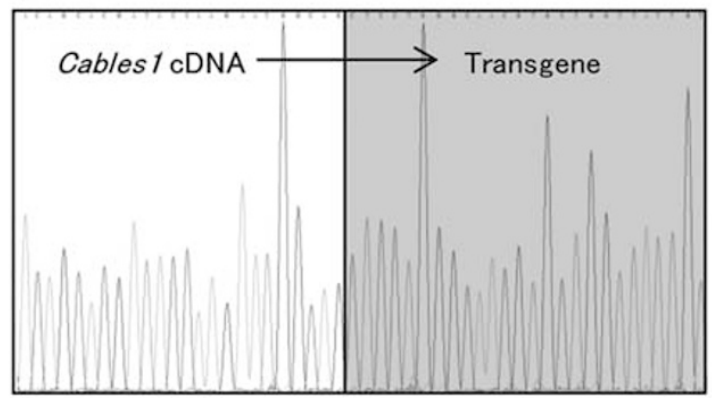

Figure 4 Mutated Cables1 mRNA in TAS. (a) Northern blot analysis of Cables1 in the fetal cerebrum of wild-type and TAS mice. Shorter mRNA derived from TAS was detected only with the $5^{\prime}$-cDNA probe. (b) cDNA sequencing analysis. The transgenic sequence (gray background) was directly connected (arrow) to the $3^{\prime}$-end of exon 3 (white background). (c) Three schematic diagrams indicating isoform I, isoform II, and TAS mutant Cables 1 mRNA. Gray and white boxes indicate untranslated region and coding sequence, respectively. (d) Three variants of Cables 1 protein were expressed in HEK293T cells. These proteins were analyzed by western blotting. Cables $1^{\text {TAS }}$ protein was smaller than the wild type. UTR, untranslated region; CDS, coding sequence.

and c). A search in the UCSC genomic database (http:// genome.ucsc.edu/) indicated that there are 14 genes in this genomic region. Figure $2 \mathrm{~d}$ shows that there were no tran- scriptional differences between wild-type and homozygous TAS mice for any of these genes except Cables1. Furthermore, we confirmed that there were no differences in the 

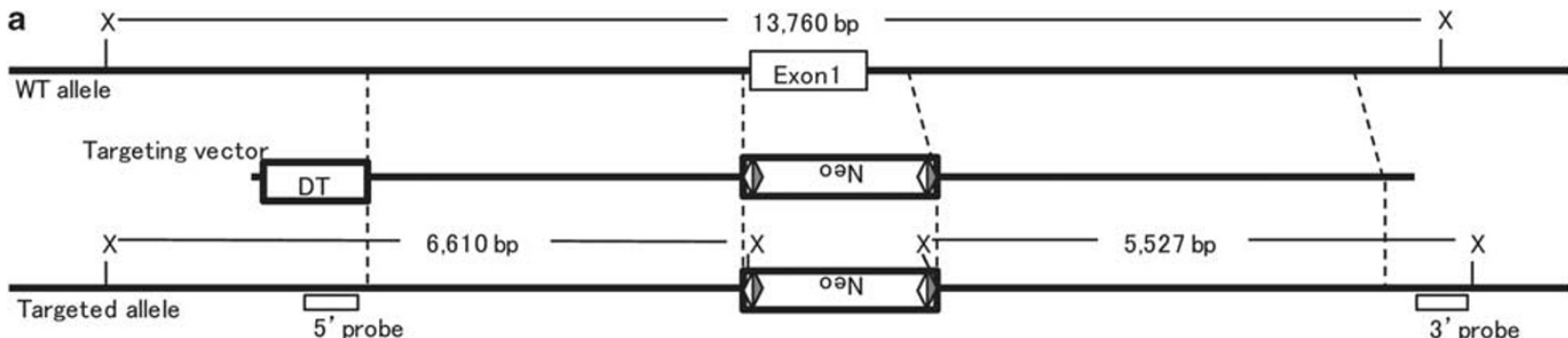

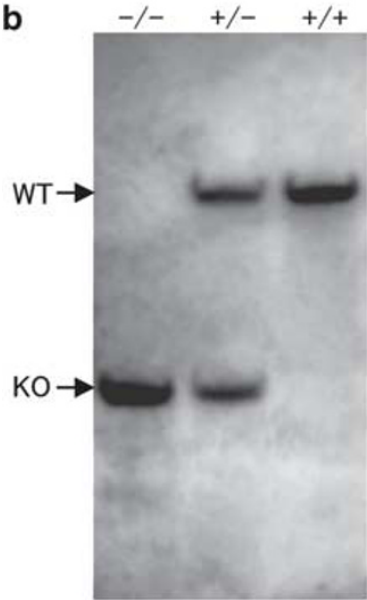

5' probe

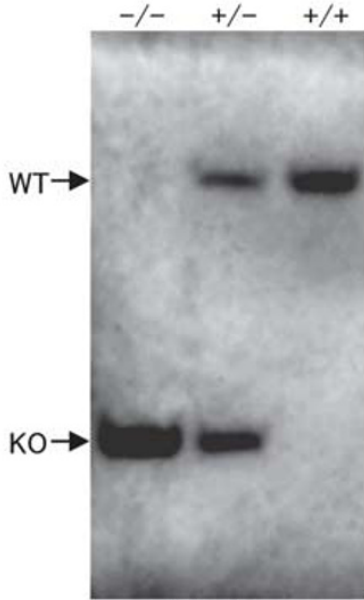

3' probe

C

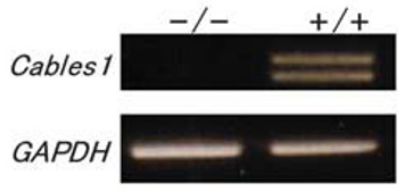

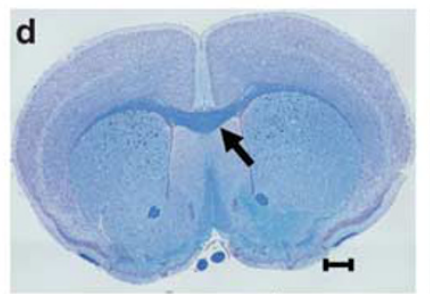

Cables1+1+

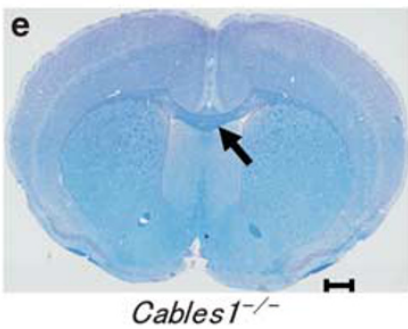

Cables $1^{-1-}$

Figure 5 Cables 1-null mutant mouse. (a) Schematic of the null allele in which exon 1 was deleted by homologous recombination in BALB/c ES cells. X, Xbal site; Neo, neomycin resistance cassette; DT, diphtheria toxin cassette; white triangle, LoxP; gray triangle, FRT. (b) Southern blotting of genomic DNA derived from Cables $1^{+/+}$, Cables $1^{-1+}$, and Cables $1^{-1-}$ mice. (c) RT-PCR of Cables 1 from exon 2 through exon 7 demonstrated the absence of both isoform I and isoform II Cables 1 products in Cables $1^{-1-}$ mice. Coronal sections through the rostral levels of the cerebrum in adult Cables $1^{+/+}$ (d) and Cables $1^{-/-}$(e) mice were stained with Klüver-Barrera (KB). Arrows indicate the corpus callosum; scale bar $=1 \mathrm{~mm}$.

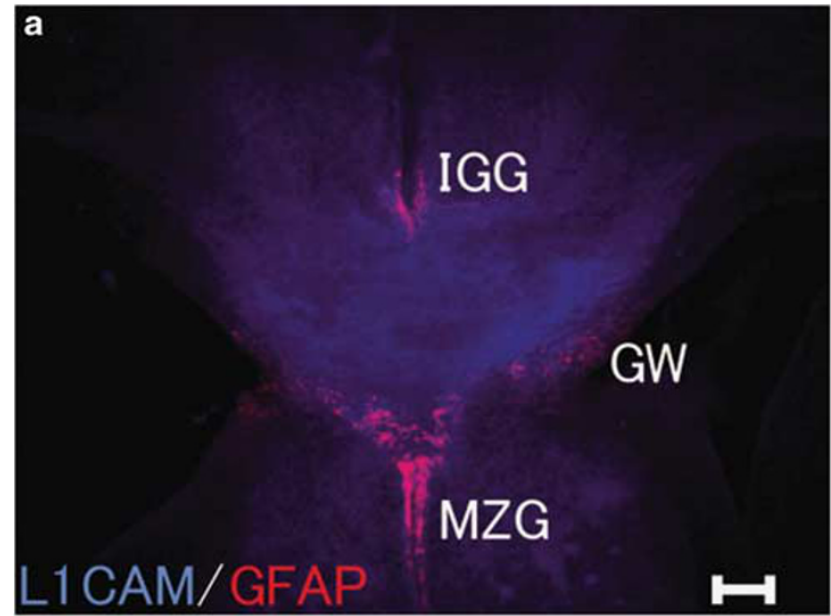

Cables $1^{-1+}$

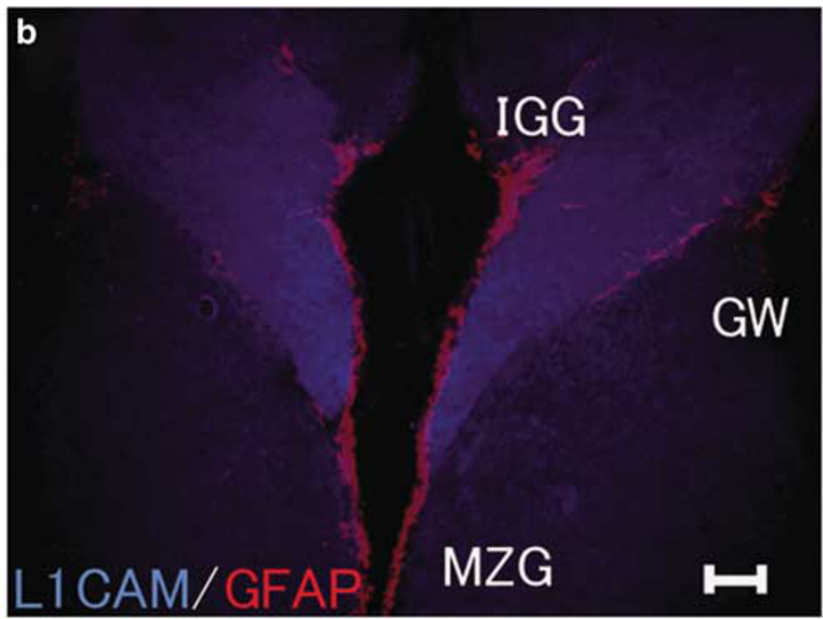

Cables $1^{-}$TAS

Figure 6 ACC in Cables $1^{-\pi A S}$. Coronal sections in P0 Cables $1^{-1+}$ (a) and Cables $1^{-\pi A S}$ (b). Staining with antibodies against L1CAM (blue) and GFAP (red). Callosal axons did not cross the midline, and GFAP-expressing IGG and MZG were indistinguishable from Cables $1^{-\pi A S}$ (b). GW, glial wedge; IGG, indusium griseum glia; MZG, midline zipper glia; scale bar $=100 \mu \mathrm{m}$.

expression of 32 additional genes located in the vicinity of the candidate region between wild-type mice and homozygous TAS mice (data not shown). These results indicate that only Cables1 is disrupted by transgene insertion, suggesting that ACC is caused by Cables 1 gene mutation in TAS mice.

A complete CABLES1 is also present in the human genome and is mapped to the long arm of chromosome 18 at 
20.71-20.84 Mb from the centromere (http://genome.ucsc.edu). CABLES1, originally called $i K 3-1$, has been isolated using the yeast two-hybrid system with cyclin-dependent kinase 3 (CDK3) cDNA as bait to evaluate cdk3 function. ${ }^{30}$ In addition to the interaction with CDK3, CABLES1 is functionally connected to p53 and p73 in cell death, suggesting that it is a molecule involved in harmonizing cell cycle progression and cell death. ${ }^{31}$ Previous studies showed that Cables1-null mutant mice displayed increased cellular proliferation (eg, endometrial hyperplasia, colon cancer, and oocyte development). ${ }^{27-29}$ In contrast to Cables 1 loss-of-function mutation, overexpression of Cables1 in a colon cancer cell line showed tumor suppressor activity, including inhibition of colony formation and cell growth. ${ }^{32}$ However, there have been no reports that aberrant expression of Cable1 is involved in neural defects in vivo.

Zukerberg et $a l^{33}$ showed that Cables 1 is expressed in the brain, where it is present in postmitotic neurons of the cerebral cortex, and interacts directly with Cdk5 and Abll (Abelson murine leukemia viral oncogene homolog 1) in the brain lysate. Furthermore, Cables 1 and Cdk5 were localized

Table 1 Frequency of ACC in Cables 1-mutant mice

\begin{tabular}{|c|c|c|}
\hline Genotype & No. of mice examined & No. of mice with ACC (\%) ${ }^{\mathrm{a}}$ \\
\hline Cables1 ${ }^{+/+}$ & 59 & $0(0 \%)^{b}$ \\
\hline Cables $1^{+}$TAS & 37 & $23(62 \%)^{b}$ \\
\hline Cables $1^{\text {TASTAS }}$ & 12 & $12(100 \%)^{b}$ \\
\hline Cables1-1- & 7 & $0(0 \%)$ \\
\hline Cables $1^{-\pi \text { TAS }}$ & 6 & $6(100 \%)$ \\
\hline
\end{tabular}

${ }^{a}$ No. of mice with $\mathrm{ACC} / \mathrm{no}$. of mice examined.

${ }^{\mathrm{b}}$ These data were reported in our previous study. ${ }^{25}$ at the tips of growing axons. They suggested that the association of Cables 1 and Cdk5 is part of the signaling pathway that operates during brain development. Moreover, Rhee et $a l^{34}$ demonstrated that Cables1 is the essential molecule connecting Robo-associated Abl and N-cadherinassociated $\beta$-catenin. Slit/Robo signaling is known to play a crucial role in cortical axon guidance across the corpus callosum by the midline glial population. ${ }^{35}$ This is the first report regarding a Cables 1 allele associated with an acallosal phenotype. We also clearly showed that a novel Cables 1 mutation in TAS mice generates a truncated Cables1 product. These observations strongly suggest that Cables1 may be involved in development of the carpus callosum.

We produced a unique Cables1-null mutant strain derived from BALB/c ES cells to evaluate Cables1 function in BALB/c mice, because it is known that the genetic background has a strong influence on the development of ACC in mice. ${ }^{12}$ Unexpectedly, the complete loss-of-function Cables1 mutant showed no alterations in callosal formation in mice, even with the same genetic background as TAS mice. Although we cannot as yet provide direct evidence for the lack of phenotype in the loss-of-function Cables1 mutant, the discrepancy in ACC frequency between Cables ${ }^{+/ T A S}$ mice $(62 \%)$ and Cables1 $1^{- \text {TAS }}$ mice $(100 \%)$ is suggestive of the possible mechanism. In mice, expression of truncated Cables1 resulted in acallosal brain development and Cables $1^{\text {TAS }}$ gene dosage was associated with the incidence of ACC, indicating a dominant negative function of Cables $^{T A S}$ on callosal formation. In contrast, the absence of Cables1 had no negative influence on brain development, suggesting the presence of a molecule(s) functionally redundant to Cables1. Furthermore, the significantly lower frequency of ACC in Cables $1^{+/ T A S}$ mice compared with Cables $1^{-/ T A S}$ mice indicated that the wild-type Cables1 serves to form the corpus callosum. Therefore, one copy of Cable ${ }^{\text {TAS }}$ may be sufficient to impair the function of the homozygous redundant gene. This speculation is summarized in Figure 7.

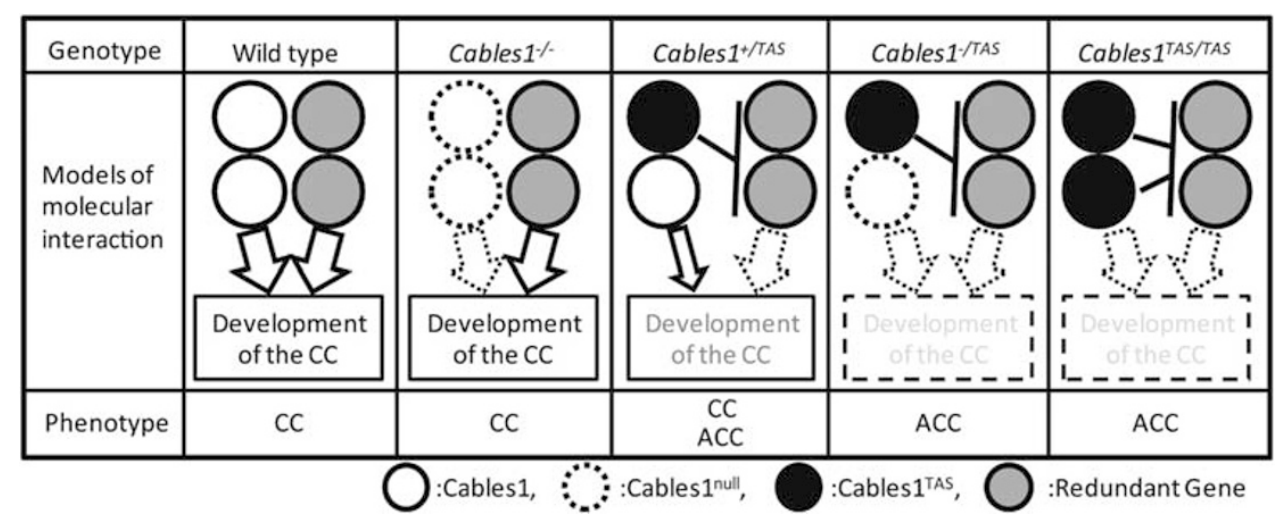

Figure 7 Model for gene interaction between Cables1, Cables ${ }^{\text {TAS }}$, and redundant gene. Cables1 and its redundant gene play a role in the development of corpus callosum, and Cables $1^{\text {TAS }}$ may impair redundant gene function. As the redundant gene functions in development of the corpus callosum, ACC was not observed in Cables 1-null mutant mice. In heterozygous TAS mice (Cables $1^{+/ T A S}$ ), even though redundant gene function was impaired by Cables $1^{\text {TAS }}$, one copy of the Cables 1 gene served to form the corpus callosum. In contrast, all Cables $1^{\text {TASTAS }}$ and Cables $1^{-\pi A S}$ mice showed ACC because Cables 1 and its redundant gene were not expressed or were impaired by Cables $1^{\text {TAS }}$, respectively. 
The Cables family has two members in mammals, designated as Cables1 and Cables2, and the latter is a possible candidate with functional redundancy. Cables 2 was cloned by crosshybridization with Cables1 and RT-PCR. ${ }^{36}$ It has been reported that Cdk5 and Abl1 associate with Cables2, similar to Cables1. Furthermore, Cables2 is expressed in a variety of tissues, including the brain. Although no data have been reported regarding colocalization of Cables1 and Cables2 expression in the brain, the effect of Cables1 dysfunction may be masked by a redundant function of Cables2 in callosal development.

Integration of adhesive interactions with directional information from attractive and repulsive cues is essential for the correct progression of callosal axons. Cables1 connects Robo-associated Abl and $\mathrm{N}$-cadherin-associated $\beta$-catenin. Truncated Cable1 includes the N-terminal half (298 amino acids) of the wild-type protein (568 amino acids). Cables 1 lacking the $\mathrm{N}$-terminal one-third of the protein shows markedly decreased association with Abll compared with the wild type. ${ }^{33}$ Although the precise localization of Abll interaction site(s) of Cables1 is unknown, five of the six SH3 domain-binding motifs (PXXP) in Cables1 are located in the $\mathrm{N}$-terminal region. The $\mathrm{SH} 3$ domain regulates the kinase activity by interacting with the kinase domain. ${ }^{37}$ Cables $1^{\text {TAS }}$ also contains PXXP domains. The function of Abl1 may be affected by binding to the truncated Cables1. The Abl family of nonreceptor tyrosine kinases consists of Abl1 and its paralog Abl2. Although Abl1-deficient mice show normal brain formation, mice lacking both Abll and Abl2 kinases develop neurulation defects at $11 \mathrm{dpc}$, suggesting that both kinases play fundamental roles in central nervous system development and function. ${ }^{38}$ Therefore, truncated Cables1 may target both Abll and Abl2. Further studies are required to determine whether both Abl kinases contribute to the corpus callosum organization in cerebral cells expressing Cables 1 after $15 \mathrm{dpc}$ and whether truncated Cable1 impairs the functions of both Abl kinases.

In conclusion, the results presented here clearly indicated that ACC in TAS mice is caused by a novel mutant gene Cables $1^{T A S}$. Although the molecular mechanisms underlying the observed effects of truncated Cables1 and its related proteins are unclear, these findings will contribute to our understanding of corpus callosum development.

Supplementary Information accompanies the paper on the Laboratory Investigation website (http://www.laboratoryinvestigation.org)

\section{ACKNOWLEDGMENTS}

This work was supported by Grants-in-Aid for Scientific Research (B) (to KY) and Challenging Exploratory Research (to FS and KY) from the Ministry of Education, Culture, Sports, Science, and Technology. We thank the members of the Yagami Laboratory for helpful discussions and encouragement.

\section{DISCLOSURE/CONFLICT OF INTEREST}

The authors declare no conflict of interest.
1. Aboitiz F, Scheibel AB, Fisher RS, et al. Fiber composition of the human corpus callosum. Brain Res 1992;598:143-153.

2. Livy DJ, Schalomon PM, Roy M, et al. Increased axon number in the anterior commissure of mice lacking a corpus callosum. Exp Neurol 1997;146:491-501.

3. Richards LJ, Plachez C, Ren T. Mechanisms regulating the development of the corpus callosum and its agenesis in mouse and human. Clin Genet 2004;66:276-289.

4. Guillem $P$, Fabre B, Cans $C$, et al. Trends in elective terminations of pregnancy between 1989 and 2000 in a French county (the Isère). Prenat Diagn 2003;23:877-883.

5. Wang LW, Huang CC, Yeh TF. Major brain lesions detected on sonographic screening of apparently normal term neonates. Neuroradiology 2004;46:368-373.

6. Bodensteiner J, Schaefer GB, Breeding L, et al. Hypoplasia of the corpus callosum: a study of 445 consecutive MRI scans. J Child Neurol 1994;9:47-49.

7. Jeret JS, Serur D, Wisniewski $K$, et al. Frequency of agenesis of the corpus callosum in the developmentally disabled population as determined by computerized tomography. Pediatr Neurosci 1985-1986;12:101-103.

8. Barkovich AJ, Norman D. Anomalies of the corpus callosum: correlation with further anomalies of the brain. AJR Am J Roentgenol 1988;151:171-179.

9. Donahoo AL, Richards $\amalg$. Understanding the mechanisms of callosal development through the use of transgenic mouse models. SeminPediatr Neurol 2009;16:127-142.

10. Zembrzycki A, Griesel G, Stoykova A, et al. Genetic interplay between the transcription factors Sp8 and Emx2 in the patterning of the forebrain. Neural Dev 2007;30:2-8.

11. Jones L, López-Bendito G, Gruss P, et al. Pax6 is required for the normal development of the forebrain axonal connections. Development 2002;129:5041-5052.

12. Hide T, Hatakeyama J, Kimura-Yoshida C, et al. Genetic modifiers of otocephalic phenotypes in Otx2 heterozygous mutant mice. Development 2002;129:4347-4357.

13. Wahlsten D, Bishop KM, Ozaki HS. Recombinant inbreeding in mice reveals thresholds in embryonic corpus callosum development. Genes Brain Behav 2006;5:170-188.

14. Kadowaki $\mathrm{M}$, Nakamura $\mathrm{S}$, Machon $\mathrm{O}$, et al. $\mathrm{N}$-cadherin mediates cortical organization in the mouse brain. Dev Biol 2007;304:22-33.

15. Shu T, Sundaresan V, McCarthy MM, et al. Slit2 guides both precrossing and postcrossingcallosal axons at the midline in vivo. J Neurosci 2003;23:8176-8184.

16. Andrews W, Liapi A, Plachez C, et al. Robo1 regulates the development of major axon tracts and interneuron migration in the forebrain. Development 2006;133:2243-2252.

17. Serafini T, Colamarino SA, Leonardo ED, et al. Netrin-1 is required for commissural axon guidance in the developing vertebrate nervous system. Cell 1996;87:1001-1014.

18. Fazeli A, Dickinson SL, Hermiston ML, et al. Phenotype of mice lacking functional Deleted in colorectal cancer (Dcc) gene. Nature 1997; 386:796-804.

19. Ren $T$, Zhang J, Plachez $C$, et al. Diffusion tensor magnetic resonance imaging and tract-tracing analysis of Probst bundle structure in Netrin1- and DCC-deficient mice. J Neurosci 2007;27: 10345-10349.

20. Raper JA. Semaphorins and their receptors in vertebrates and invertebrates. Curr Opin Neurobiol 2000;10:88-94.

21. Piper M, Plachez C, Zalucki $O$, et al. Neuropilin 1-Sema signaling regulates crossing of cingulate pioneering axons during development of the corpus callosum. Cereb Cortex 2009;19(Suppl 1):i11-i21.

22. Mendes SW, Henkemeyer M, Liebl DJ. Multiple Eph receptors and B-class ephrins regulate midline crossing of corpus callosum fibers in the developing mouse forebrain. J Neurosci 2006;26: 882-892.

23. Woychik RP, Alagramam K. Insertional mutagenesis in transgenic mice generated by the pronuclear microinjection procedure. Int J Dev Biol 1998;42:1009-1017.

24. Jaenisch R. Transgenic animals. Science 1998;240:1468-1474.

25. Mizuno $S$, Mizobuchi A, Iseki $H$, et al. A novel locus on proximal chromosome 18 associated with agenesis of the corpus callosum in mice. Mamm Genome 2010;21:525-533. 
26. lijima $S$, Tanimoto $Y$, Mizuno $S$, et al. Effect of different culture conditions on establishment of embryonic stem cells from BALB/CAJ and NZB/BINJ mice. Cell Reprogram 2010;12:679-688.

27. Zukerberg LR, DeBernardo RL, Kirley SD, et al. Loss of cables, a cyclindependent kinase regulatory protein, is associated with the development of endometrial hyperplasia and endometrial cancer. Cancer Res 2004;64:202-208.

28. Kirley SD, D’Apuzzo M, Lauwers GY, et al. The Cables gene on chromosome $18 \mathrm{Q}$ regulates colon cancer progression in vivo. Cancer Biol Ther 2005;4:861-863.

29. Lee HJ, Sakamoto $H$, Luo H, et al. Loss of CABLES1, a cyclin-dependent kinase-interacting protein that inhibits cell cycle progression, results in germline expansion at the expense of oocyte quality in adult female mice. Cell Cycle 2007;6:2678-2684.

30. Matsuoka M, Matsuura Y, Semba K, et al. Molecular cloning of a cyclinlike protein associated with cyclin-dependent kinase 3 (cdk 3 ) in vivo. Biochem Biophys Res Commun 2000;273:442-447.

31. Tsuji K, Mizumoto K, Yamochi T, et al. Differential effect of ik3-1/ cables on p53- and p73-induced cell death. J Biol Chem 2002;277: 2951-2957.
32. Park do $\mathrm{Y}$, Sakamoto $\mathrm{H}$, Kirley $\mathrm{SD}$, et al. The Cables gene on chromosome $18 \mathrm{q}$ is silenced by promoter hypermethylation and allelic loss in human colorectal cancer. Am J Pathol 2007;171: 1509-1519.

33. Zukerberg LR, Patrick GN, Nikolic M, et al. Cables links Cdk5 and c-Ab and facilitates Cdk5 tyrosine phosphorylation, kinase upregulation, and neurite outgrowth. Neuron 2000;26:633-646.

34. Rhee J, Buchan T, Zukerberg L, et al. Cables links Robo-bound Abl kinase to $\mathrm{N}$-cadherin-bound beta-catenin to mediate Slit-induced modulation of adhesion and transcription. Nat Cell Biol 2007;9:883-892.

35. Shu T, Richards LJ. Cortical axon guidance by the glial wedge during the development of the corpus callosum. J Neurosci 2001;21:2749-2758.

36. Sato $H$, Nishimoto I, Matsuoka M. ik3-2, a relative to ik3-1/cables, is associated with cdk3, cdk5, and c-abl. Biochim Biophys Acta 2002;1574:157-163.

37. Mayer BJ, Baltimore D. Mutagenic analysis of the roles of $\mathrm{SH}_{2}$ and $\mathrm{SH}_{3}$ domains in regulation of the Abl tyrosine kinase. Mol Cell Biol 1994;14:2883-2894.

38. Koleske AJ, Gifford AM, Scott ML, et al. Essential roles for the Abl and Arg tyrosine kinases in neurulation. Neuron 1998;21:1259-1272. 